Ko, Y.J. et al. (2017). Determinants of consumer attitude toward corporate sponsors: A comparison between profit and non-profit sport event sponsorship. Journal of Consumer Behaviour, 16: 176-186. http://dx.doi.org/10.1002/cb.1622

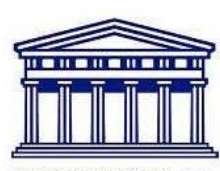

UNIVERSITY of the WESTERN CAPE

\title{
Determinants of consumer attitude toward corporate sponsors: A comparison between a profit and non-profit sport event sponsorship
}

Yong Jae Ko, Yonghwan Chang, Chanmin Park and Frikkie Herbst

\begin{abstract}
The purposes of the present study were to identify key attributes of sponsors that positively influence consumers' attitude formation and to examine the moderator role of sport event types (nonprofit vs. profit). Based on the theories of range and selective attention, we hypothesized that consumers weigh differently on particular sponsorship attributes depending on event type (i.e., profit vs. nonprofit) in constructing their attitude. The study utilized multi-group structural equation modeling on data collected by questionnaire survey from a total of 505 spectators of college sport event $(n=303)$ and FIFA World Cup $(n=202)$. Results of structural equation modeling test indicate that prominence of sponsors is an important predictor of consumer attitude in both events, while sincerity of sponsors was found to be important in local and amateur college sport event sponsorship. From a theoretical perspective, the current study sheds light on sponsorship study, particularly the importance of examining sponsor characteristics in predicting consumer attitude and the event type as a moderating variable. A key practical implication is that sport managers should carefully examine consumers' perceptions toward sponsor characteristics in making their event sponsorship decisions.
\end{abstract}

In the past three decades, sponsorships have evolved into a major standalone global industry and commercial investment opportunity (Wallister, 2003). This is attributed to the advantages corporate sponsorships offer for both sponsor and sport properties, and to the increased recognition of sponsorship as a valuable form of corporate communication and business-to-business activity (Dolphin, 2003; Crompton, 2004). Worldwide sponsorship spending had reached \$51.1bn in 2012 and was projected to reach \$6o.2bn in 2016 despite the economic difficulties (IEG, 2016). Even though the sponsorship market continues to grow, they are being focused on several markets such as sports, entertainment, causes, arts, and festivals. The primary recipient of sponsorship spending is sport properties, with approximately 70 per cent of all sponsorship spending being directed to sports (IEG, 2016).

A considerable amount of literature on sponsorship effectiveness supports the contention that sport sponsorship helps enhance corporate image and creates sales opportunities through increased awareness and loyalty among target consumers (Cornwell and Coote, 
2005; Ko et al., 2008). Specifically, in the (sport) marketing and advertising literature, numerous researchers have provided empirical support for the positive influence of sponsorship for corporate sponsors including (i) increased brand exposure/recall/awareness (Javalgi et al., 1994; Lardinoit and Derbaix, 2001; Cornwell et al., 2005b; Ko et al., 2008), (ii) enhanced image of sponsors and their products (Javalgi et al., 1994; Stipp and Schiavone, 1996; Gwinner and Eaton, 1999), (iii) increased positive attitudes toward the corporate sponsor (Nicholls et al., 1994; Till and Busler, 2000; Kim and Na, 2007), and (iv) stock price increase (Cornwell et al., 2005a; Kudo et al., 2015). Therefore, a variety of organizations in different industry sectors intend to associate with sport properties that have an attractive consumer base for their products (Ferreira et al., 2008), and consider sport sponsorships as a valuable method to reach new markets and retain an existing customer base (Shank and Lyberger, 2015). In exchange for such benefits, sport properties receive financial benefits, in-kind resources, or an image association with their corporate partners (McDaniel, 1999).

In the sponsorship literature, prior studies argue that consumer attitudes toward corporate sponsors and their brands are major outcome variables (Speed and Thompson, 2000; Madrigal, 2001; Simmons and Becker-Olsen, 2006; Ko and Kim, 2014) and, at the same time, a key antecedent of sponsorship success (Stipp and Schiavone, 1996). Thus, when evaluating sponsorship effectiveness, scholars and practitioners need to carefully select and measure specific variables that significantly influence consumer attitude and behavior (Speed and Thompson, 2000; Cornwell et al., 2005b); after all, it is the current and potential consumers of the sponsored events who are also the target markets of the corporate sponsors (Meenaghan, 2001).

Speed and Thompson (2000) proposed and tested a comprehensive framework in their seminal work of sponsorship effectiveness. The framework incorporates key determinants of consumer (interest - i.e., attention, favorability, and willingness to use sponsor's product): (i) event factors (status of event and personal liking for the event); (ii) sponsor factors (attitude, sincerity, and ubiquity of sponsor); and (iii) sponsor-event fit. Although the authors tested and generally supported efficacy of attitude, sincerity, and ubiquity of sponsors in predicting favorable outcomes (e.g., favorability), "attitude to sponsor" (sponsor factor) and "favorability" (sponsorship response) were not clearly differentiated from each other; attitude was measured by several items reflecting favorability.

To further examine the specific characteristics of sponsors is necessary not only to clearly explain consumers' attitude toward sponsors (Johnson and Zinkhan, 1990; Speed and Thompson, 2000) and overall sponsorship (Ko and Kim, 2014) but also to explain their impact on consumers' attitudes toward the event property (Ruth and Simonin, 2003). In their seminal work of sponsorship effectiveness, Speed and Thompson (2000) proposed and tested a comprehensive framework that incorporates key determinants of consumer responses (i.e., attention, favorability, and willingness to use sponsor's product). They are categorized into (i) event factors (status of event and personal liking for the event), (ii) sponsor factors (attitude, sincerity, and ubiquity of sponsor), and (iii) sponsor-event fit. 
Although their results generally supported efficacy of attitude, sincerity, and ubiquity of sponsors in predicting favorable outcomes (e.g., favorability), "attitude to sponsor" (sponsor factor) and "favorability" (sponsorship response) were not clearly differentiated from each other; attitude was measured by several items reflecting favorability.

Additionally, several scholars noted that consumers' sponsor evaluation mechanisms can vary depending on the event types (Gwinner, 1997; Ko and Kim, 2014). Recently, collaborative relationships between businesses and non-profits are increasing in number, but the dynamics of such relationships differ from business-business collaboration (Sagawa and Segal, 2000; Wymer Jr and Samu, 2003). While a main motivation of business-tobusiness relationships is to develop new markets and products (Cunningham and Varadarajan, 1995), corporate sponsors could be more interested in public relations objective or in being socially responsible through such cross-sector relationships (Himmelstein, 1997; Wymer Jr and Samu, 2003). In nonprofit sponsorship literature, Ko and Kim (2014) highlighted the importance of corporate sponsorship in nonprofit sector such as college sport programs and suggest that sponsor characteristics (e.g., sincerity) are important consideration when there is no high fit between sponsors and event property. To fully understand consumers' responses toward sponsors and sponsorship, corporate sponsors and event managers must carefully examine both specific characteristics of sponsors and event property types. However, systematic investigation of such event characteristics (i.e., profit vs. nonprofit sport event), particularly as moderator in the relationship between sponsor characteristics and attitude toward sponsors, has not been explored in the context of sport event sponsorship to date.

In response to the call for more systematic research addressing the gaps in the existing sponsorship literature, the researchers in the current study developed and tested a research model focusing on the relationship between consumer perceptions toward four salient characteristics of sponsors (i.e., prominence, ubiquity, sincerity, and congruence) and their overall attitude toward sponsors. The researchers also examined how these relationships operate differently depending on a particular sport event type (profit vs. nonprofit) in more detail. In particular, the purpose of this article is to examine a fundamental, yet unexplored, question: Do consumers respond differently to corporate sponsors of profit-oriented sport event than they do to nonprofit sport event sponsors? The results of this study make theoretical contributions to sponsorship and consumer behavior literature by offering new insights on the key determinants of consumers' sponsorship response, corresponding to the event type. In the following sections, detailed information of theoretical background and research hypothesis is addressed.

\section{Theoretical background and hypothesis development Consumer attitude toward sponsors}

A primary goal of sponsorship involvement is to create a positive consumer attitude toward a sponsor and/or its brand. In their sequential approach of beliefs, attitudes, and behavioral intentions, Fishbein and Ajzen (1975) suggest that an attitude to engage in some behavior is a function of an individual's beliefs and the theoretical relationship between 
attitude and behavior was further confirmed (Ajzen and Fishbein, 1977). According to theory of planned behavior, developing a positive attitude toward an organization is important as it directly influences consumer purchase intention and ultimately consumption behavior (Ajzen, 1991, 2001).

In marketing and advertising literature, prior studies have shown that attitudinal variables are important predictors of behavioral intentions (e.g., Shimp, 1981; MacKenzie et al., 1986; MacKenzie and Lutz, 1989). MacKenzie and Lutz (1989) found that attitude toward an advertisement has a significant and positive influence on attitude toward the brand, and indirectly affects purchase intention through affecting the consumers' attitude toward the brand (MacKenzie et al., 1986). Karson and Fisher (2005) found a significant and direct affect that attitude toward the web advertisement had on purchase intention. In brand management literature, brand attitude has been found to be an important predictor of behavioral intentions (Burton et al., 1998; Chang and Ko, 2014). Keller (1993) argued that consumers with favorable brand attitude tend to be more agreeable to paying premium prices for that brand. Therefore, it is likely that consumers' attitudes toward a specific brand are positively related to their intentions to purchase the brand.

In the sport sponsorship literature, prior studies considered consumer attitude toward corporate partners and their brands, events, and sponsorship in general as a major target of evaluation (Speed and Thompson, 2000; Madrigal, 2001; Ruth and Simonin, 2003; Dalakas and Levin, 2005; Eagleman and Krohn, 2012; Ko and Kim, 2014). In the context of collegiate sport sponsorship, Madrigal (2001) found that sport fans' favorable beliefs about the benefits derived by a corporate sponsorship are positively related to attitude toward sponsors' products. The relationship is significantly moderated by fan identification. By surveying NASCAR fans, Dalakas and Levin (2005) found that consumers develop positive attitude toward sponsors when sponsors support their favorite drivers, and develop negative attitudes when the sponsors support their least favorite driver. Eagleman and Krohn (2012) also found a significant relationship between fan identification and attitude toward sponsors. Another group of scholars focused on corporate image and found that positive images of a sponsor directly influenced purchase intention of that sponsor's products (Sandler and Shani, 1993; Nicholls et al., 1994; Turco, 1995; Pope and Voges, 2000; Ko et al., 2008).

However, since Speed and Thompson (2000) and Ko and Kim (2014), there has not been a follow-up study that systematically examines the influence of specific sponsor characteristics in predicting consumers' attitude toward sponsors. In particular, the differential impact of sponsor characteristics on consumers' attitudes toward the sponsors in profit and nonprofit event contexts is lacking. Against this background, the researchers included consumers' attitudes toward a corporate sponsor as the main dependent variable in the proposed research model. 


\section{Antecedents of sponsor attitude \\ Perceived market prominence}

Market prominence refers to "variations in market prominence (reputation) of potential sponsors as a source of information when inferring the identity of event sponsors" (Pham and Johar, 2001:124). In other words, market prominence is consumers' perceptions of the reputation of sponsors or brands influenced by brand awareness, market share, and visibility (Johar et al., 2006). In the sponsorship context, Johar et al. (2006) found that consumers tend to be more likely to identify a prominent aspect of a sponsor or brand.

In their recent empirical study, Ko and Kim (2014) incorporated prominence as a key sponsor characteristic along with sincerity and ubiquity and confirmed that prominence is the most important sponsor characteristic that forms consumers' sponsor perception. This finding is consistent with a previous study, which found that consumers were more likely to identify prominent sponsors. This is true especially in "cluttered" media environments in which it is difficult for consumers to make associations between particular sponsors and events (Pham and Johar, 2001). Therefore, the first hypothesis was developed.

H1: Consumers' perceived prominence of the sponsor in the market is positively related to their attitude toward the sponsor.

\section{Perceived ubiquity of sponsor}

The second variable, ubiquity, is considered as consumers' perceptions of the frequency and selectivity of a firm's sponsorship involvement (Speed and Thompson, 2000). Speed and Thompson (2000) suggested that ubiquity is a critical component that determines how the sponsors are perceived. Regarding the direction of the ubiquity and the consumer perception, the results from previous studies including Speed and Thompson (2000) were inconclusive. Speed and Thompson argued that respondents do not respond strongly to sponsorship by firms that they perceived to be engaging in a large number of sponsorships simultaneously, and hypothesized that perceived ubiquity of the sponsor is negatively associated with the level of sports sponsorship response.

However, the consumers might interpret the ubiquity as evidence demonstrating the success and the financial soundness of the firm, which in turn can be translated into positive image of the firms (Shimp, 2013). In the classic learning condition, repeated exposure to stimuli led to a positive affective reaction (Zajonc, 1968). In a similar manner to sponsor exposure, Baker (1999) also found that repetition of the stimulus was essential to increase the likelihood of a successful recall and attract the respondent's attention. Therefore, we specify the direction of influence of ubiquity in the hypothesis.

H2: Consumers' perceived ubiquity of the sponsor is positively related to their attitude toward the sponsor. 


\section{Perceived sincerity of sponsor}

Perceived sincerity of sponsors was proposed as one of the key antecedents of consumers' attitudes toward sponsors. Prior studies found that consumers' sincerity perceptions are positively related to their attitudes toward the sponsorship (Speed and Thompson, 2000; Rifon et al., 2004). That is, a sponsor that is perceived to be a sincere partner of a given team or event is more likely to receive more positive responses from consumers (e.g., willingness to consider the sponsor's brand or products), when compared with a sponsor that is perceived to be a corporation with only commercial consideration.

Similarly, prior studies also found that consumers develop positive attitudes and increase purchase intention if sponsors are perceived to have a philanthropic motivation rather than being motivated by profit-oriented objectives (D'Astous and Blitz, 1995; Rifon et al., 2004; Becker-Olsen and Hill, 2006). Consumers perceive the sponsor as being less credible when sponsors participate in sponsorship with profit-oriented motivations (Rifon et al., 2004). This is particularly true in so-called cause-related sponsorship arrangements (Stipp and Schiavone, 1996; Rifon et al., 2004; Becker-Olsen and Hill, 2006). Hence, we hypothesize:

H3: Consumers' perceived sincerity of the sponsor is positively related to their attitudes toward the sponsor.

\section{Perceived sponsor-property congruence}

The term congruence refers to "relatedness," "similarity," or "fit" (Bhat and Reddy, 1998; Johar and Pham, 1999; Rifon et al., 2004; Rodgers, 2004; Becker-Olsen and Hill, 2006). The perceived congruence between the sponsor and the sponsored property is one of the most important characteristics that help develop positive consumer attitude (Stipp and Schiavone, 1996; Bhat and Reddy, 1998; Gwinner and Eaton, 1999; Johar and Pham, 1999; Rifon et al., 2004; Cornwell et al., 2005b; Simmons and Becker-Olsen, 2006). For example, Rolex sponsoring a golf tournament conveys the qualities of elegance, luxury, and accuracy embodied by Rolex. Such symbolic (i.e., image of accuracy) or functional (i.e., a shoe company and a marathon event) characteristics establish the congruence or fit between the sponsor and the sponsored property (Bhat and Reddy, 1998; Speed and Thompson, 2000). Congruence might also refer to credibility and cause (Rifon et al., 2004), or simply a semantic relationship between an event and the sponsoring company (e.g., the Super Bowl and automobile company; Johar and Pham, 1999).

Benefits of having congruence include increased sponsor recall and effective image transfer (Gwinner and Eaton, 1999). For example, Stipp and Schiavone (1996) found those consumers who perceived a strong relationship between the sponsoring brand and the Olympics could recall Olympic sponsors. This image transfer process can be enhanced when there is perceived "congruence" between the image or function of the event and that of the sponsor. Even though properties cannot give a sponsor an image that it does not authentically have, sport sponsorship can help shape an otherwise obscure sponsor image, or reinforce existing images of the sponsor (Woisetschlager and Michaelis, 2012). On the basis of these findings, the following hypothesis is proposed: 
H4: Consumers' perceived fit between the sponsor and the sponsored property is positively related to their attitudes toward the sponsor.

Moderation effect of event type on consumer responses Event types should be carefully examined in the sponsorship research because they impact consumers' overall assessment of the event's image (Gwinner, 1997). For example, in the comparison between FIFA World Cup and University football events, there may be a number of event characteristics that uniquely shape consumer responses toward sponsors. On the one hand, the FIFA World Cup is an international and professional sporting event that attracts numerous global companies. According to a recent IEG press release (2010), FIFA secured $\$ 1.6 \mathrm{bn}$ in World Cup sponsorship revenue through three sponsorship tiers: FIFA Partners (annual fee between $\$ 24 \mathrm{~m}$ and $\$ 44 \mathrm{~m}$ ), FIFA World Cup Sponsors (annual fee between $\$ 10 \mathrm{~m}$ and $\$ 25 \mathrm{~m}$ ), and National Supporters (annual fee between $\$ 4.5 \mathrm{~m}$ and $\$ 7.5 \mathrm{~m}$ ). Because this type of sponsorship is mainly commercially driven, return on investment can be an important outcome to sponsors.

On the other hand, college sports are local and amateur sporting events that usually attract local and regional sponsors, and occasionally global sponsors. A football team from a Division I-A university was chosen as the focal sport team of the study. In this study, 16 per cent of total annual revenue $(\$ 118,208,000)$ was generated from sponsorship and royalties. Firms increasingly recognize the collegiate sport fans as a valuable target market (Sabri et al., 2008; Masterralexis et al., 2009). In this type of event property, sincerity is an important factor of sponsors that form positive consumer attitude (Kim et al., 2011). The sponsors might have philanthropic motivation in sponsorship involvement in addition to commercially driven objectives.

In spite of little sponsorship research having been performed on examining the moderation effects of event type on consumer responses, there are several theoretical backdrops supporting the moderation effects. First, according to the range theory (Yeung and Soman, 2005) from consumer psychology and marketing, consumers may respond differently to the same information depending on their own psychological range or anchor of the information. Specifically, when consumers evaluate alternatives, they first identify what they believe to be the most or least important attributes of the alternatives, which determines a psychological range of acceptance for each alternative. The range then serves as a context for evaluating the alternatives; for example, consumers may relatively weigh largely on prominence in the case of FIFA World Cup events as opposed to collegiate sports events.

The theory of selective attention championed by Machintosh (1975) shares similar theoretical meaning with the psychological anchoring effects. One fundamental assumption of this theory is that consumers selectively pay attention to a particular attribute of an object when the attribute can uniquely explain or provide sufficient information about the 
object; then, the increased attention to a specific attribute increases favorable evaluative judgment (Janiszewski et al., 2013).

In the context of celebrity endorsement, Chang et al. (2014) formulated attentional determinants (i.e., expertise of athlete/product quality, attractiveness of athlete/product design, and popularity of athlete and product) of endorsement effectiveness. The authors compared three distinctive markets (i.e., Japan, Korea, and USA) and found that even for the same endorsement contract, consumers evaluate the endorsement uniquely depending on their attentional focus (e.g., Asians-expertise vs. Americans-attractiveness). Additionally, in their lab experiment, Chang and Ko (2016) showed a strong empirical evidence of attentional influence on endorsement effectiveness; even a low fit between endorsers and endorsed brands leads to favorable consumer responses through different attentional processes. In the context of nonprofit sponsorship, consumers may selectively and largely attend to the sincerity or philanthropic aspect of non-profit sponsorship more so than sponsorship alliance between corporate partners and global sport events (e.g., Olympics and FIFA World Cup).

Based on this background, it is assumed that consumers' responses toward sponsorship information might be different depending on the characteristics of sponsors and the type of property. In our study, consumers may selectively and largely attend to the sincerity or philanthropic aspect of the collegiate sponsorship more so than the consumers of FIFA World Cup events. Therefore, it is hypothesized that:

H5: Event type plays a moderating role in the relationship between consumers' perceptions of the sponsors and their attitudes toward the sponsors.

\section{Method}

\section{Participants and procedures}

For college sport sponsorship, spectators of a football event in an NCAA Football Bowl Subdivision University in the USA were recruited during the 2010-2011 season. In this study, firms in various industries were included as focal sponsors to reduce the industryspecific characteristics that might have an unexpected impact on the hypothesized relationship between the constructs of research interest (Kim et al., 2011). Specifically, the sponsors were actual partners from 10 industries (i.e., automobile, internet, sport diet supplements, apparel/shoes, restaurants, groceries, broadcasting, insurance, banking, and wireless carriers), all of which provided products and services appropriate for purchase by students. Doctoral students (interviewers) intercepted attendees after the completion of a match and circulated face-to-face self-administered questionnaires. Participants were asked to choose only one sponsor and to provide their opinion of the sponsor. They were informed that participation in the study was entirely voluntary and unpaid and were given an explanation of the purpose of the research and brief instruction on how to complete the questionnaire. On average, it took 10 minutes to complete each questionnaire. Out of a total of 319 cases returned, 16 questionnaires were deemed unusable owing to invalid responses. These were discarded, leaving 303 usable surveys. About 61 per 
cent of them were female. The largest number of participants was Caucasian (50\%), followed by Hispanic (31\%), Asian (8\%), African-American (8\%), and other (3\%).

For the 2010 FIFA World Cup sponsorship, the sponsors were 16 partners from 10 industries (i.e., automobile, alcoholic beverage, apparel/shoes, airline, consulting, consumer electronics, credit card, energy, (fast) food, and mobile phone). Spectators in South Africa were recruited by following the similar procedure. Participation in the study was entirely voluntary and unpaid, and they were given an explanation of the purpose of the research and brief instruction on how to complete the questionnaire. Master of business administration students (interviewers) intercepted attendees inside of the 2010 FIFA World Cup stadium before the match started, during half-time, and after the completion of the match. The interviewers explained the purpose and anonymous nature of the research and asked whether the respondents were willing to participate. If consent was given, a brief description of instruction was provided on how to compete the questionnaire. Respondents took on average 8-10 minutes to complete the questionnaire. A total of 202 usable samples were included in the data analysis. The majority of the participants $(70 \%)$ were male, and most of the participants were Caucasian (87\%). In the South African context, non-White includes Black, Indian/Asian, and Coloreds. Ranging in skin tone from very pale to darkest brown, many colored was (and still is) indistinguishable from their White or Black compatriots (http://www.economist. com/node/21546062). The average number of games attended in the 2010 FIFA World Cup was two.

\section{Measures}

Measures that had previously been shown to have good psychometric properties were selected from the relevant literature. Some items were modified to suit the context of the current study. All items were then reviewed by a five-member panel of scholars with relevant expertise in the conceptual and methodological issues of the present study, following which items were refined. Then, a confirmatory factor analysis (CFA) was performed to further establish validity of the scale items. As a result, a total of 20 items were retained, as follows:

1. ubiquity: three items (adapted from Speed and Thompson, 2000);

2. sincerity: four items (adapted from Speed and Thompson, 2000);

3. prominence: four items (adapted from Johar et al., 2006); and

4. sponsor-property congruence: five items (adapted from Speed and Thompson, 2000);

5. attitude: four items (Lee and Cho, 2009).

The response format for all items (except those for "attitude") was a 7-point Likert-type scale ( $1=$ strongly disagree; 7 = strongly agree). Only the items for "attitude" were measured by 7 -point semantic differential scale items $(1=$ bad, $7=$ good; $1=$ unfavorable, $7=$ favorable; $1=$ negative, 7 = pos- itive; 1 = dislikable, 7 = likable; Table 1 ). Items measuring demographic characteristics of participants were also included in the questionnaire. To avoid response bias from order effect, we randomly placed the items in the questionnaire. Specific information about validity and reliability of scale measures is discussed in the Results section. 


\begin{tabular}{|c|c|c|c|c|c|c|}
\hline \multicolumn{2}{|c|}{ Factors and items } & \multirow{2}{*}{$\frac{\lambda}{0.84}$} & \multirow{2}{*}{$\frac{\text { Mean }}{6.1}$} & \multirow{2}{*}{$\begin{array}{c}\text { SE } \\
0.04\end{array}$} & \multirow{2}{*}{$\frac{\mathrm{CR}}{0.88}$} & \multirow{2}{*}{$\frac{\mathrm{AVE}}{0.71}$} \\
\hline Prominence & The firm is highly regarded in the industry & & & & & \\
\hline & The firm is one of the most capable firms in the industry & 0.80 & 5.8 & 0.04 & & \\
\hline & The firm has good products/service & 0.89 & 5.9 & 0.04 & & \\
\hline \multirow[t]{3}{*}{ Ubiquity } & This firm sponsors many different sports & 0.68 & 5.3 & 0.04 & 0.86 & 0.67 \\
\hline & It is very common to see this firm sponsoring sport events & 0.87 & 5.6 & 0.04 & & \\
\hline & I expect this firm to sponsor major sport events & 0.83 & 4.8 & 0.04 & & \\
\hline \multirow[t]{3}{*}{ Sincerity } & $\begin{array}{l}\text { The main reason the firm would sponsor AAA is because the firm believes } \\
\text { this event deserves support }\end{array}$ & 0.65 & 4.8 & 0.04 & 0.74 & 0.49 \\
\hline & This sponsor would be likely to have the best interest of AAA at heart & 0.80 & 4.7 & 0.04 & & \\
\hline & This firm would probably support AAA even if it had much lower profile & 0.64 & 4.4 & 0.04 & & \\
\hline \multirow[t]{3}{*}{ Fit } & There is a logical connection between AAA and the sponsor & 0.79 & 5.1 & 0.04 & 0.84 & 0.64 \\
\hline & The image of AAA and the image of the sponsor are similar & 0.81 & 4.9 & 0.04 & & \\
\hline & The sponsor and AAA stand for similar things & 0.80 & 4.9 & 0.04 & & \\
\hline \multirow[t]{3}{*}{ Attitude } & Overall, my attitude toward the firm sponsoring AAA is & & & & & \\
\hline & Bad/good & 0.96 & 5.9 & 0.04 & 0.93 & 0.87 \\
\hline & Dislikable/likable & 0.90 & 5.9 & 0.04 & & \\
\hline
\end{tabular}

Note: $\mathrm{SE}=$ standard error; $\mathrm{CR}=$ construct reliability; $\mathrm{AVE}=$ average variance extracted; $\mathrm{AAA}=$ American Automobile Association.

\section{Data analysis}

For the purpose of the study, two sponsored events of collegiate (amateur and local event) and professional (professional and international event) sports can be viewed as treatments. The authors were interested in exploring both treatment and moderated effects on the structural relationship between the perceptions of a sponsor and the consumer attitudes toward that sponsor. The authors coded sponsored event type as a dummy variable equivalent to one if the participants select FIFA and zero if the participants select the college sport event. Then, we estimated both the average treatment effect (ATE; Austin, 2011) and moderated effects using multiple-group structural equation modeling (SEM; Kaplan, 2009). We analyzed the data using R 2.15.2 (R Development Core Team, 2012).

\section{Results}

\section{Measurement model}

The measurement model was developed by incorporating aforementioned scale items and tested through CFA. Table 1 shows factor loadings, means, standard errors, and construct reliability values. The model showed a good fit: $\chi^{2} / d f=146.01 / 67=2.18$; comparative fit index $(\mathrm{CFI})=0.98$; Tucker - Lewis index $=0.98$; root mean squared error of approximation $($ RMSEA $)=0.05$; standardized root mean square residual $=0.03$ (Hair et al., 2009). The reliability was examined by using Cronbach's alpha coefficient and average variance extracted (AVE) for each factor; the construct reliability ranged from 0.74 (sincerity) to 0.93 (attitude), and AVE measures were close to or greater than the 0.50 standard (Hair et al., 2009) and ranged from 0.49 (sincerity) to 0.87 (attitude). The results indicate that the items used in the present study have reliability and validity in measuring key constructs. All factor loadings were greater than a conservative threshold of 0.70 (Hair et al., 2009), except for three items. An acceptable CFA model fit and high factor loadings provided empirical evidence of convergent validity of the measures in each construct. Factor correlations among sponsorship factors were relatively high (ranging from 0.30 between prominence and ubiquity to 0.50 between prominence and fit), and the comparison between the squared correlations among the constructs and AVE values 
provide empirical evidence of discriminant validity of the measurement scale (Hair et al., 2009; Kline, 2011).

\section{The assessment of invariance}

We conducted the invariance test to evaluate whether the proposed measurement model for the latent variables was statistically equivalent across the two groups. For the examination of measurement equivalence, all participants $(N=505)$, initially combined for comparison purpose, were classified into two independent groups based on the sponsored event type (i.e., consumers for college events, $n=303$; FIFA World Cup, $n=202$ ). A series of hierarchically nested multiple-group CFA models (Kaplan, 2009) were tested following established procedures (Netemeyer et al., 2003).

The hierarchy began with a test of configural invariance (Meredith, 1993) using a multiplegroup CFA model that specified the same pattern of zero and non-zero factor loadings for both groups, but non-zero factor loadings, intercepts, and means were allowed to vary across groups. This model was used as a baseline to compare subsequent models in the hierarchy. The results of the configural invariance model showed an acceptable fit to the data $\left(\chi^{2} / d f=279.17 / 134=2.08, \mathrm{CFI}=0.97, \mathrm{RMSEA}=0.07\right)$. To test weak factorial invariance, we constrained factor loadings to be equal across groups. By nesting this level of invariance within model 1 , the difference in the chi-square statistic was significant, $x^{2}$ $(\Delta d f=9)=32.88, \quad p<0.05$, indicating that constraining factor loadings equality reduces model fit. However, because there was no substantial difference in RMSEA ( $\triangle$ RMSEA $=$ 0.002), we concluded that there was no appreciable difference in the factor loadings across groups (Chen, 2007). To test strong factorial invariance, we constrained factor loadings and intercepts to be invariant across groups. By nesting this level of invariance within model 1, the difference in the chi-square statistic was also significant, $x^{2}(\Delta d f=18)=65.19, \quad p<0.05$. However, constraining factor loadings and intercepts to equality did not reduce model fit substantially in RMSEA ( $\triangle$ RMSEA $=0.005$ ) (e.g., changes $\leq$ 0.010 in RMSEA indicates invariance; Chen 2007); there was no appreciable difference in the intercepts across groups (Cheung and Rensvold, 2002). Therefore, the comparison of the model fit between the baseline model and the model with constrained factor loadings and intercepts across groups indicates that strong factorial invariance holds with this sample (Table 2). This level of factorial invariance allows for a valid comparison between means of latent variables across groups.

\section{Treatment and moderated effects}

To estimate the treatment (i.e., ATE) and moderating effects of sponsored event type between sponsor characteristics and attitude, we fitted the multiple-group SEM shown in Figure 1 using maximum likelihood estimation and the package lavaan in $\mathrm{R}$ (Rosseel, 2012). 


\begin{tabular}{|c|c|c|c|c|c|c|c|}
\hline Model & $\chi^{2}$ & $d f$ & RMSEA & CFI & Model comparison & $\begin{array}{l}\text { Difference } \\
\text { in } \chi^{2} / d f\end{array}$ & $\begin{array}{r}\text { Difference } \\
\text { in RMSEA }\end{array}$ \\
\hline 1. Configural invariance & 279.17 & 134 & 0.066 & 0.966 & - & - & - \\
\hline 2. Factor loadings invariant & 312.05 & 143 & 0.068 & 0.961 & $2-1$ & $32.88 / 9^{*}$ & 0.002 \\
\hline 3. Factor loadings and intercepts invariant & 344.36 & 152 & 0.071 & 0.955 & $3-1$ & $65.19 / 18 *$ & 0.005 \\
\hline
\end{tabular}

Note: Changes of $\leq 0.010$ in RMSEA indicate invariance (Chen 2007).

RMSEA = root mean squared error of approximation; $\mathrm{CFI}=$ comparative fit index ${ }^{*} p<0.05$.

To obtain the ATE, we estimated the latent mean difference in sponsorship response between the college group and the FIFA group. In multiple-group SEM, this is accomplished by setting the latent mean of one group to zero, while the latent mean of the other group becomes the latent mean difference between groups (Loehlin, 2012). The authors also used the multiple-group SEM to estimate the differences in latent means between college and FIFA groups for the exogenous factors. For the multiple-group SEM fit, the overall goodness-of-fit statistics for the unconstrained baseline structural model showed an acceptable fit of the data $\left(\chi^{2}=279.17, d f=134, \chi^{2} / d f=2.08\right.$, CFI $=0.97$, Tucker-Lewis index $=0.95$, RMSEA $=0.07$, standardized root mean square residual $=$ 0.04). Fit statistics, parameter estimates, and standard errors for the models are depicted in Table 3 and Figure 1.

Given that strong factorial invariance holds for the latent variables of interest, we estimated the latent mean of the private group by constraining both factor loadings and intercepts to be equal across groups and the latent mean of the college group to equal zero. The differences between latent means were obtained in standard deviation units (i.e., Cohen's $D$; Cohen, 1988). The results showed that the differences between the latent means of ubiquity $(-0.15, p=0.11)$ and sincerity $(-0.13, p=0.24)$ were not statistically significant. However, for the FIFA group, the latent means for prominence $(-0.46, p<0.001)$, fit $(-$ 0.34, $p=0.01)$, and attitude toward sponsor $(-0.38, p<0.001)$ were significantly lower than the latent means of the college group.

To test whether the structural coefficients between the constructs in the FIFA group were similar to those in the college samples, we added constraints on structure coefficients. The difference in the chi-square statistic was significant $\left(X^{2}[4]=11.26, p=0.02\right)$, showing that the causal links in Figure 1. Multiple-group structural equation model to estimate average treatment effect of event characteristics and moderated effects. Note. Quantities next to ellipses are latent mean differences between college event and FIFA by constraining both factor loadings and intercepts to be equal across group and the latent mean of college group to zero. Estimates are presented with standard errors between parentheses; standardized structural coefficients for college group/structural coefficients for FIFA group. ${ }^{* *} p<0.01 ;{ }^{* * *} p<0.001$. the structural model were significantly different between the two samples. The chi-square difference was performed again to identify which of the structural coefficients were different between the groups. Despite the fact that a significant difference in the chi-square statistic was only found for the individual path between sincerity and 
attitude toward sponsor, there were differences in significance tests for paths of individual groups. Specifically, for the college group, prominence $(\beta=0.60, p<0.001)$ and sincerity ( $\beta=0.45, p=0.001$ ) of the sponsor significantly influenced their attitude toward sponsor, while ubiquity $(\beta=0.20, p=0.09)$ and fit $(\beta=-0.31, p=0.11)$ were not significant. For the FIFA group, prominence $(\beta=0.61, p<0.001)$ of the sponsor significantly influenced their attitude toward sponsor, while ubiquity $(\beta=0.02, p=0.86)$, sincerity $(\beta=0.11, p=0.31)$, and fit $(\beta=0.15, p=0.38)$ were not significant.

\section{Discussion}

\section{Theoretical implications}

In the current study, the authors examined the relationship between consumers' perception toward selected key attributes of sponsors and their attitudes by focusing on two distinct types of sporting events. To accomplish the purposes of the research, we performed a series of analyses. First, the authors developed and tested a measurement model to capture consumers' perceptions toward event sponsors by combining salient sponsor characteristics suggested in the sponsorship literature (e.g., Speed and Thompson, 2000) and the perceived congruence between the sponsor and property, a core aspect of the sponsorship effectiveness.

The initial measurement model fitted the data adequately, which indicates that the measurement scale possesses sound psychometric properties. Specifically, all factor loadings were significantly higher than zero, which provided evidence for the convergent validity of the measurement scale. AVE values and reliability coefficients were also higher than the suggested threshold. Reasonable levels of factor correlations provided support for discriminant validity (Hair et al., 2009). The results of invariance test indicated that the proposed measurement model for the latent variables was statistically equivalent across the two groups. Taken together, it was deemed reasonable to use them to test the structural model. This result also supported that the prominence is a critical aspect of sponsor characteristics.

After examining hypothesized relationships through a simultaneous equations analysis, multiple-group SEM was employed to test the moderating effect of event type. The overall goodness-of-fit statistics showed a good fit of the model to the data. The results imply that consumers' attitudes toward sponsors in the two different events are dissimilarly influenced by the characteristics of sponsors. Specifically, for the college group (nonprofit sponsorship), prominence and sincerity of the sponsor significantly influenced sponsor attitude, while ubiquity and fit were not significant. For the FIFA group (profit sponsorship), only prominence of the sponsor significantly influenced attitude toward the sponsor, while ubiquity, sincerity, and fit were not significant. 


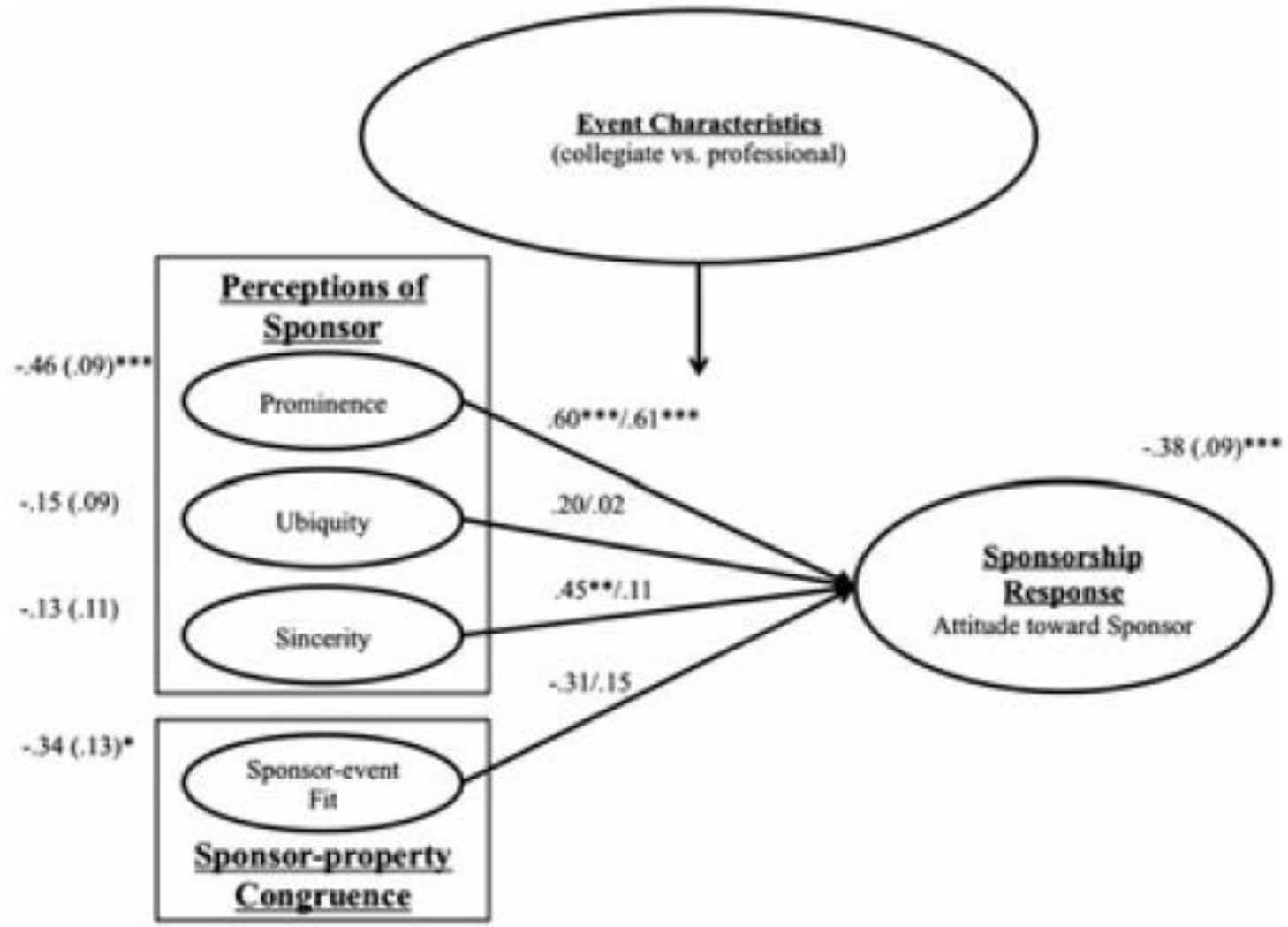

Figure 1. Multiple-group structural equation model to estimate average treatment effect of event characteristics and moderated effects. Note. Quantities next to ellipses are latent mean differences between college event and FIFA by constraining both factor loadings and intercepts to be equal across group and the latent mean of college group to zero. Estimates are presented with standard errors between parentheses; standardized structural coefficients for college group/ structural coefficients for FIFA group. ${ }^{* *} p<0.01 ;{ }^{* * *} p<0.001$. 


\begin{tabular}{|c|c|c|c|c|}
\hline \multirow[b]{2}{*}{ Model } & \multirow[b]{2}{*}{ Model fit indices } & \multirow{2}{*}{$\begin{array}{l}\text { Model comparison } \\
\text { in } \chi^{2} / d f\end{array}$} & \multicolumn{2}{|c|}{ Structural coefficients } \\
\hline & & & $Z=1$ (SE) & $Z=0$ (SE) \\
\hline 1. Unconstrained & $\begin{array}{l}\chi^{2}(134)=279.17, \mathrm{CFI}=0.97, \mathrm{TLI}=0.95, \\
\mathrm{RMSEA}=0.066, \mathrm{SRMR}=0.039\end{array}$ & - & - & - \\
\hline 2. Structural weight & $\begin{array}{l}\chi^{2}(134)=279.17, \mathrm{CFI}=0.97, \mathrm{TLI}=0.95, \\
\mathrm{RMSEA}=0.066, \mathrm{SRMR}=0.039\end{array}$ & $2-1: 11.26 / 4^{*}$ & - & - \\
\hline $\begin{array}{l}3 . \\
\text { Prominence } \rightarrow \text { Attitude }\end{array}$ & $\begin{array}{l}\chi^{2}(134)=279.17, \mathrm{CFI}=0.97, \mathrm{TLI}=0.95, \\
\mathrm{RMSEA}=0.066, \mathrm{SRMR}=0.039\end{array}$ & $3-1: 3.22 / 1$ & $0.60(0.12)^{* * *}$ & $0.61(0.17)^{* * *}$ \\
\hline 4. Ubiquity $\rightarrow$ Attitude & $\begin{array}{l}\chi^{2}(134)=279.17, \mathrm{CFI}=0.97, \mathrm{TLI}=0.95, \\
\mathrm{RMSEA}=0.066, \mathrm{SRMR}=0.039\end{array}$ & $4-1: 2.39 / 1$ & $0.20(0.18)$ & $0.02(0.22)$ \\
\hline 5. Sincerity $\rightarrow$ Attitude & $\begin{array}{l}\chi^{2}(134)=279.17, \mathrm{CFI}=0.97, \mathrm{TLI}=0.95, \\
\mathrm{RMSEA}=0.066, \mathrm{SRMR}=0.039\end{array}$ & $5-1: 5.57 / 1^{*}$ & $0.45(0.19)^{* *}$ & $0.11(0.19)$ \\
\hline 6. Fit $\rightarrow$ Attitude & $\begin{array}{l}\chi^{2}(134)=279.17, \mathrm{CFI}=0.97, \mathrm{TLI}=0.95, \\
\mathrm{RMSEA}=0.066, \mathrm{SRMR}=0.039\end{array}$ & $6-1: 0.69 / 1$ & $-0.31(0.29)$ & $0.15(0.30)$ \\
\hline
\end{tabular}

Note: $\mathrm{SE}=$ standard error; $\mathrm{CFI}$, comparative fit index; TLI, Tucker-Lewis index; RMSEA = root mean squared error of approximation; SRMR, standardized root mean square residual.

${ }^{*} p<0.05$.

$* * p<0.01$.

**** $p<0.001$.

Therefore, hypotheses 1 and 3 were supported. The significant moderation effect of event type supported hypothesis 5: event type plays a moderating role in the relationship between consumers' perceptions of the sponsors and their attitudes toward the sponsors.

The results offer several meaningful theoretical implications. In a similar manner with the theory of selective attention (Machintosh, 1975; Janiszewski et al., 2013; Chang et al., 2014; Chang and Ko, 2016), consumers indeed weighed differently on particular sponsor attributes depending on event type in constructing their evaluative judgment (attitude). Specifically, the results of the current study showed that sincerity was not an important sponsor attribute in the profit sport event context, while the same attribute significantly influenced consumers' attitude construction in the nonprofit event sponsorship. This result partially supports several existing findings that suggest consumers' sincerity perception is an important predictor of their sponsor attitudes (Speed and Thompson, 2000; Rifon et al., 2004; Kim et al., 2011). Particularly, in the context of amateur and local event (nonprofit), consumers are likely to develop positive attitudes toward sponsors when they perceived that sponsors are sincere partners of a given team or event. In other words, consumers develop positive attitudes when sponsors have sincere motive in sponsorship involvement (Rifon et al., 2004). Consumers' perceived market prominence was found to be an important predictor of consumer attitudes in both event types. This result supports that consumers are more likely to identify a prominent aspect of a sponsor (Johar et al., 2006) and this attention developed positive attitude toward sponsors (Janiszewski et al., 2013). Based on this result, we argue that it is important to measure prominence of sponsor in the future sponsorship evaluation research. On the other hand, perceived fit between the sponsor and the sponsored property was found to be insignificant in shaping consumers' attitude toward sponsors in both events. However, the significantly different latent means between the events indicate that prominence and fit were evaluated in favorable manners for college sport sponsors than those of FIFA World Cup events. In other words, prominence and fit are more critical requirements in profit-oriented sponsorship; again, hypothesis 5 was supported. 
The range theory (Parducci, 1965; Yeung and Soman, 2005) as previously discussed also provides theoretical explanation to the results. That is, when consumers evaluate a sponsorship, they evaluate a particular attribute of a sponsor based on their own psychological ranges or expectations (Yeung and Soman, 2005). In other words, consumers may expect extreme values in sponsor characteristics such as prominence or fit in the case of FIFA World Cup events as an international and high profile property. Therefore, consumers' expectations, acceptance levels, or subjective anchors for the FIFA sponsors' characteristics would be higher than those of the collegiate events sponsors' characteristics; thus, consumers showed lower perceptions/ evaluations for the FIFA sponsors' characteristics, although their actual values in terms of prominence and sponsor-property fit were high. However, paradoxically, the lower latent means of prominence and fit in FIFA group may reflect that the two attributes are more important in professional and international sporting event contexts owing to consumers' high levels of expectations.

In terms of perceived ubiquity, the researchers could not find any significant relationship between consumers' attitude and perceptual differences between events, which does not support hypothesis 2. This result is inconsistent with that of the existing studies (Zajonc, 1968; Baker, 1999; Shimp, 2013). According to Speed and Thompson (2000), the underlying rationale of the non-significances would be that consumers tend to respond weakly toward sponsorship activations when they perceive sponsors to be engaged in a large number of sponsorships simultaneously. In this case, ubiquity can even create negative impacts on perceptions of the sponsor because consumers are more likely to view the sponsors' motives as self-interested and profit oriented rather than interpret the ubiquity as evidence demonstrating the success and the financial soundness of the firm (Shimp, 2013). Therefore, the non-significant study should be further investigated and may warrant future endorsement/sponsorship studies.

\section{Managerial implications}

A quintessential need for any firm is to differentiate itself from other competitors via a competitive advantage. A successful sport sponsorship can be an effective mechanism in creating and sustaining this advantage (Amis et al., 1997). In the midst of today's harsh economic environment, however, current and prospective sponsors must make challenging decisions about whether to invest their resources in sport sponsorships and then determine the types of event properties.

The current study, along with previous research, should be regarded as one of the many steps necessary to clearly understand the formation of consumers' attitudes in sport sponsorship. From a sport event manager's perspective, because sponsorship revenue is extremely important for the success of the business, they need to develop long-term and successful relationships with carefully selected sponsors. This research emphasizes the need for event managers to work alongside sponsors to develop an effective strategy that will maximize benefits to both parties. 
One implication of the current study is that sport managers should look carefully at whether a particular sponsor should be approached or not and for what reasons. From a consumer's attitudinal perspective, results of the current study indicate that sponsor characteristics are very important to examine because they form consumers' overall attitudes toward the sponsor. Particularly, market prominence was found to be an important sponsor characteristic in both profit and nonprofit sport sponsorship. This is true especially in "cluttered" media environments in which it is difficult for consumers to make associations between particular sponsors and events. Other characteristics of sponsors examined in the current study are also making differential impact on consumers' evaluations of sponsors. For example, perceived sincerity was an important sponsor characteristic in the context of nonprofit sponsorship, such as college sport events. In this case, consumers are likely to have lowered defense mechanisms in processing marketing communication through sponsorship involvement. As such, managers of nonprofit events may also consider inviting even relatively low-profile local businesses to build corporative relationship and encourage them to clearly communicate their sincere motivation with a variety of stakeholders including their consumers and fans. Such approaches are equally important to corporate partners when making important decisions to choose their partners.

\section{Limitations and future research direction}

It is very important to evaluate sponsorship from the consumers' lens. The current study needs to be expanded by focusing on how consumers' judgment within their subjective ranges corresponds to their objective evaluations in shaping their responses toward sponsor and collaborative relationships. Specifically, future studies may explore other important antecedents (e.g., industry category and profit-orientation of sponsors; size and levels of the event - local vs. national and international; platform - event vs. team sponsorship) of consumer attitude to expand our theoretical understanding of the effectiveness of sponsorship involvement. In this effort, event classification methods (e.g., profit vs. nonprofit, local vs. global, professional vs. amateur, and team vs. event) should be further articulated as it might offer alternative explanations or mechanisms when interpreting the results and addressing managerial implications. Additionally, consumers' purchase intentions need to be incorporated as a dependent variable along with their sport involvement and commitment to a particular team and brands as moderators.

It is also necessary to measure the degree to which respondents were exposed to sponsorship at the time of response and if consumers' perceive nonprofit sponsorship is sincerer than profit sponsorship. Sponsor awareness and brand familiarity and actual brand consumption experiences need to be measured and controlled to accurately interpret the results. Additionally, while our investigation occurred within specific sporting event contexts, we believe there is a fruitful research opportunity to replicate our study in differing event contexts using a broader sample. In consideration of the unequal gender distribution of samples in the current study, such replications will enhance external validity of the core aspects of our research model and help generalize research findings. Clearly, a host of research opportunities remain to be explored. 


\section{Biographical notes}

Dr. Yong Jae Ko is an associate professor in the Department of Tourism, Recreation, and Sport Management (TRSM) at the University of Florida, USA. He has been involved in numerous research projects that relate to the sports consumers' decision-making process, which focused on socio-psychological variables that influence sport consumption behavior. Specifically, his research includes consumer attitudes, quality and value perceptions, and beliefs about sport organizations and their brands, in addition to their psychological characteristics, such as needs and motivation, personality, and involvement.

Dr. Yonghwan Chang is an assistant professor in the Department of Kinesiology and Sport Management at Texas Tech University, USA. His research interests are sport marketing and consumer behavior focused on implicit memory and experiential consumption. Also, his research includes social networks, mass media data mining, and integrative analysis with propensity score methods and multilevel modeling.

Dr. Chanmin Park is an assistant professor in the Sport Science and management at Nanyang Technological University, Singapore. His research includes consumer behavior, awareness of and compliance with statutes, standards, and guidelines; injury and death prevention in sport and physical activity; and factors influencing sport event quality and management.

Dr. Frikkie Herbst is a professor in the School of Business and Finance at the University of Western Cape in South Africa. His research interest is focused on marketing, marketing matrices, services marketing, and wine business. 


\section{References}

Ajzen I, Fishbein M. 1977. Attitude-behavior relations: a theoretical analysis and review of empirical research. Psychological Bulletin 84(5): 888-918.

Ajzen I. 1991. The theory of planned behavior. Organizational Behavior and Human Decision Processes 5O(2): 179-211. DOI:10.1016/0749-5978(91)90020-T.

Ajzen I. 2001. Nature and operation of attitudes. Annual Review of Psychology 52: 27-58. DOI:10.1146/annurev.psych.52.1.27.

Amis J, Pant N, Slack T. 1997. Achieving a sustainable competitive advantage: a resourcebased view of sport sponsorship. Journal of Sport Management 11: 80-96.

Austin PC. 2011. An introduction to propensity score methods for reducing the effects of confounding in observational studies. Multivariate Behavioral Research 46: 399424. DOI:10.1080/00273171.2011.568786.

Baker WE. 1999. When can affective conditioning and mere exposure directly influence brand choice? Journal of Advertising 28 (4): 31-46. DOI:10.1080/00913367.1999.10673594.

Becker-Olsen KL, Hill RP. 2006. The impact of sponsor fit on brand equity: the case of nonprofit service providers. Journal of Service Research 9: 73-83. DOI:10.1177/1094670506289532.

Bhat S, Reddy SK. 1998. Symbolic and functional positioning of brands. Journal of Consumer Marketing 15: 32-43. DOI:10.1108/07363769810202664.

Burton S, Lichtenstein DR, Netemeyer RG, Garretson JA. 1998. A scale for measuring attitude toward private label products and an examination of its psychological and behavioral correlates. Journal of the Academy of Marketing Science 26: 293-306. DOI:10.1177/0092070398264003.

Chang Y, Ko YJ. 2014. The brand leadership: scale development and validation. Journal of Brand Management 21: 63-80. DOI:10.1057/bm.2013.23.

Chang Y, Ko YJ. 2016. Reconsidering the role of fit in celebrity endorsement: associativepropositional evaluation (APE) accounts of endorsement effectiveness. Psychology \& Marketing 33(9): 678-691.

Chang Y, Ko YJ, Tasci A, Arai A, Kim TH. 2014. Strategic match of athlete endorsement in global markets: an associative learning perspective. International Journal of Sports Marketing and Sponsorship 15: 253-271.

Chen FF. 2007. Sensitivity of goodness of fit indexes to lack of measurement invariance. Structural Equation Modeling 14: 464-504. Cheung GW, Rensvold RB. 2002. Evaluating goodness-of-fit indexes for testing measurement invariance. Structural Equation Modeling 9: 233-255. DOI:10.1207/S15328007SEMo902_5.

Cohen J. 1988. Statistical Power Analysis for the Behavioral Sciences. Hillsdale: NJ.

Cornwell TB, Coote LV. 2005. Corporate sponsorship of a cause: the role of identification in purchase intent. Journal of Business Research 58: 268-276. DOI:10.1002/bs.3830330104.

Cornwell TB, Pruit SW, Clark JM. 2005a. The relationship between major-league sports' official sponsorship announcements and the stock prices of sponsoring firms. Journal of the Academy of Marketing Science 33(4): 401-412. 
Cornwell TB, Weeks CS, Roy DP. 2005b. Sponsorship-linked marketing: opening the black box. Journal of Advertising 34(2): 23-45. DOI:10.1016/So148-2963(03)00135-8.

Crompton J. 2004. Conceptualization and alternate operationalizations of the measurement of sponsorship effectiveness in sport. Leisure Studies 3: 267-281. DOI:10.1080/ 0261436042000183695 .

Cunningham MH, Varadarajan PR. 1995. Strategic alliances: a synthesis of conceptual foundations. Journal of the Academy of Marketing Science 23: 282-296.

D’Astous A, Blitz P. 1995. Consumer evaluations of sponsorship programmes. European Journal of Marketing 29(12): 6-22. DOI:10.1108/03090569510102504.

Dalakas V, Levin AM. 2005. The balance theory domino: how sponsorships may elicit negative consumer attitude. Advances in Consumer Research 32: 91-97.

Dolphin R. 2003. Sponsorship: perspectives on it strategic role. Corporate Communication: An International Journal 8: 173-186. DOI:10.1108/13563280310487630.

Eagleman AN, Krohn BD. 2012. Sponsorship awareness, attitudes, and purchase intentions of Road Race Series participants. Sport Marketing Quarterly 21: 210-220.

Ferreira M, Hall T, Bennett G. 2008. Exploring brand positioning in a sponsorship context: a correspondence analysis of the dew sport tour. Journal of Sport Management 22: $734-761$.

Fishbein M, Ajzen I. 1975. Belief, Attitude, Intention, and Behavior: An Introduction to Theory and Research. Addison-Wesley: Reading, MA.

Gwinner K. 1997. A model of image creation and image transfer in event sponsorship. International Marketing Review 14(3): 145-158. DOI:10.1108/02651339710170221.

Gwinner KP, Eaton J. 1999. Building brand image through event sponsorship: the role of image transfer. Journal of Advertising 28(4): 47-57. DOI:10.1080/00913367.1999.10673595.

Hair JF, Black WC, Babin BJ, Anderson RE. 2009. Multivariate Data Analysis 7th edn. Upper Saddle River, NJ: Prentice Hall.

Himmelstein JL. 1997. Looking Good and Doing Good: Corporate Philanthropy and Corporate Power. Indiana University: Indianapolis, IN.

IEG Press Releases (2010). FIFA secures $\$ 1.6$ billion in World Cup sponsorship revenue. Available at http://www.sponsorship.com/ About-IEG/Press-Room/FIFA-Secures\$1-6-Billion-in-World-Cup-Sponsorship.aspx [accessed on 31 August 2014]

IEG (2016). As sponsorship borders fall, spending rises. Available at http://www.sponsorship.com/IEGSR/2016/o1/05/As-Sponsorship-Borders-Fall,Spending-Rises.aspx [accessed on July 2 2016]

Janiszewski C, Kuo A, Tavassoli NT. 2013. The influence of selective attention and inattention to products on subsequent choice. Journal of Consumer Research 39: 1258-1274. DOI:10.1086/ 668234.

Javalgi RG, Traylor MB, Gorss AC, Lampman E. 1994. Awareness of sponsorship and corporate image: an empirical investigation. Journal of Advertising 23(4): 47-58. DOI:10.1080/00913367.1943.10673458.

Johar GV, Pham MT. 1999. Relatedness, prominence, and constructive sponsor identification. Journal of Marketing Research 36: 299-312. DOI:10.2307/3152078. 
Johar GV, Pham MT, Wakefield KL. 2006. How event sponsors are really identified: a (baseball) field analysis. Journal of Advertising 46(2): 183-198. DOI:10.2501/So02184990606020X.

Johnson M, Zinkhan GM. 1990. Defining and measuring company image. Proceedings of the Thirteenth Annual Conference of the Academy of Marketing Science, Volume XIII, New Orleans, 346-350.

Kaplan D. 2009. Structural Equation Modeling 2nd edn. Thousand Oaks, CA: Sage.

Karson EJ, Fisher RJ. 2005. Reexamining and extending the dual mediation hypothesis in an online advertising context. Psychology \& Marketing 22: 333-351. DOI:10.1002/mar.20062.

Keller LK. 1993. Conceptualizing, measuring, and managing customer-based brand equity. Journal of Marketing 57(1): 1-22. DOI:10.2307/1252054.

Kim YK, Ko YJ, James J. 2011. The impact of relationship quality on attitude toward a sponsor. Journal of Business \& Industrial Marketing 26: 566-576.

Kim Y, Na J. 2007. Effects of celebrity athlete endorsement on attitude towards the product: the role of credibility, attractiveness and the concept of congruence. International Journal of Sports Marketing and Sponsorship 8: 310-320.

Kline RB. 2011. Principles and Practice of Structural Equation Modeling $3^{\text {rd }}$ edn. New York, NY: Guilford.

Ko YJ, Kim K, Claussen CL, Kim TH. 2008. The effect of sport involvement, sponsor awareness, and corporate image on intention to purchase sponsors' products. International Journal of Sports Marketing and Sponsorship 9: 79-94.

Ko YJ, Kim YK. 2014. Determinants of consumers' attitude formation toward sport sponsorship. Journal of Nonprofit and Public Sector Marketing 26: 1-23.

Kudo M, Ko YJ, Walker M, Connaughton D. 2015. The influence of title sponsorships in sport on stock price fluctuations. International Journal of Sports Marketing and Sponsorship 16: 118-137.

Lardinoit T, Derbaix C. 2001. Sponsorship and recall of sponsors. Psychology \& Marketing 18: 167-190. DOI:10.1002/1520- 6793(200102)18:2<167::AID-MAR1004>3.0.CO;2I.

Lee HS, Cho CH. 2009. The matching effect of brand sponsorship event personality: sponsorship implications. Journal of Sport Management 23: 41-64.

Loehlin JC. 2012. Latent Variable Models: An Introduction to Factor, Path, and Structural Analysis. Erlbaum: Hillsdale, NJ.

Machintosh NJ. 1975. A theory of attention: variations in the associability of stimuli with reinforcement. Psychological Review 82: 276-298. DOI:10.1037/hoo76778.

MacKenzie SB, Lutz RJ. 1989. An empirical examination of the structural antecedents of attitude toward an ad in an advertising pretesting context. Journal of Marketing 53(2): 48-65. DOI:10.2307/1251413.

MacKenzie SB, Lutz RJ, Belch GE. 1986. The role of attitude toward the ad as a mediator of advertising effectiveness: a test of competing explanations. Journal of Marketing Research 23: 130-143. DOI:10.2307/3151660. 
Madrigal R. 2001. Social identity effects in a belief-attitude- intentions hierarchy: implications for corporate sponsorship. Psychology \& Marketing 18: 145-165. DOI:10.1002/(SICI) 1520-6793(199903)16:2<163::AID-MAR6>3.0.CO;2-Y.

Masterralexis LP, Barr CA, Hums MA. 2009. Principles and Practices of Sport Management 3rd edn. Sudbury, MA: Jones and Bartlett.

McDaniel SR. 1999. An investigation of match-up effects in sport sponsorship advertising: the implications of consumer advertising schemes. Psychology \& Marketing 16(2): 163-184. DOI:10.1002/(SICI)1520-6793(199903)16:2<163::AID-MAR6>3.0.CO;2-Y.

Meenaghan T. 2001. Understanding sponsorship effects. Psychology \& Marketing 19: 95-122. DOI:10.1002/1520-6793 (200102)18:2<95::AID-MAR1001>3.o.CO;2-H.

Meredith W. 1993. Measurement invariance, factor analysis, and factorial invariance. Psychometrika 58: 525-543. DOI:10.1007/BF02294825.

Netemeyer RG, Bearden WO, Sharma S. 2003. Scaling Procedures: Issues and Applications. Sage: London.

Nicholls J, Roslow S, Laskey H. 1994. Sports event sponsorship for brand promotion. Journal of Applied Business Research 10(4): 35-40.

Parducci A. 1965. Category judgment: a range frequency model. Psychological Review 71: 407-418. DOI:10.1037/hoo22602.

Pham MT, Johar GV. 2001. Market prominence biases in sponsor identification: processes and consequentiality. Psychology \& Marketing 18: 123-143. DOI:10.1002/15206793(200102) 18:2<123::AID-MAR1002>3.0.CO;2-3.

Pope NL, Voges K. 2000. The impact of sport sponsorship activities, corporate image, and prior use on consumer purchase intention. Sport Marketing Quarterly 9(2): 96-101.

$\mathrm{R}$ Development Core Team. 2012. $R$ : a language and environment for statistical computing (version 2.15.2) [computer software]. Vienna: $R$ Foundation for Statistical Computing.

Rifon NJ, Choi SM, Trimble CS, Li H. 2004. Congruence effects in sponsorship: the mediating role of sponsor credibility and consumer attributions of sponsor motive. Journal of Advertising 33(1): 29-42. DOI:10.1080/00913367.2004.10639151.

Rodgers S. 2004. The effect of sponsor relevance on consumer reactions to internet sponsorships. Journal of Advertising 32(4): 67-76. DOI:10.1080/00913367.2003.10639141.

Rosseel Y. 2012. lavaan: an R package for structural equation modeling. Journal of Statistical Software 48(2): 1-36.

Ruth JA, Simonin BL. 2003. Brought to you by brand A and brand B: investigating multiple sponsors' influence on consumer attitudes toward sponsorship events. Journal of Advertising 32(3): 19-30. DOI:10.1080/00913367.2003.10639139.

Sabri MF, MacDonald M, Masud J, Paim L, Hira TK, Othman MA. 2008. Financial behavior and problems among college students in Malaysia: research and education implication. Consumer Interests Annual 54: 166-170.

Sagawa S, Segal E. 2000. Common Interest, Common Good: Creating Value through Business and Social Sector Partnership. Harvard Business School: Boston, MA. 
Sandler DM, Shani D. 1993. Sponsorship and the Olympic games: the consumers' perspectives. Sport Marketing Quarterly 2(3): 38-43. Shank MD, Lyberger MR. 2015. Sports Marketing: A Strategic Perspective. Routledge: New York, NY.

Shimp TA. 1981. Attitude toward the ad as a mediator of consumer brand choice. Journal of Advertising 1O(2): 9-15. DOI:10.1080/ 00913367.1981.10672756.

Shimp TA. 2013. Advertising promotion and other aspects of integrated marketing communications. Mason, $\mathrm{OH}$ : South-Western Cengage Learning.

Simmons CJ, Becker-Olsen KL. 2006. Achieving marketing objectives through social sponsorship. Journal of Marketing 70(4): 154-169. DOI:10.1509/jmkg.70.4.154.

Speed R, Thompson P. 2000. Determinants of sports sponsorship response. Journal of the Academy of Marketing Science 28: 226-238. DOI:10.1177/0092070300282004.

Stipp H, Schiavone NP. 1996. Modeling the impact of Olympic sponsorship on corporate image. Journal of Advertising Research 36: 22-28. DOI:10.1080/00913367.2000.10673613.

Till BD, Busler M. 2000. The match-up hypothesis: physical attractiveness, expertise, and the role of fit on brand attitude, purchase intent and brand beliefs. Journal of Advertising 15(6): 1-13. DOI:10.1080/00913367.2000.10673613.

Turco DM. 1995. The effects of sport sponsorship on product recall and corporate image. In K. Grant \& I. Walker (Eds.), World Marketing Congress 7(3), Melbourne: Academy of Marketing Science.

Wallister B. 2003. An international review of sponsorship research: extension and update. International Journal of Advertising 22: 5-40.

Woisetschlager DM, Michaelis M. 2012. Sponsorship congruence and brand image. European Journal of Marketing 46: 509-523. DOI:10.1108/03090561211202585.

Wymer WW Jr, Samu S. 2003. Dimensions of business and non-profit collaborative relationships. Journal of Nonprofit \& Public Sector Marketing 11: 3-22.

Yeung WM, Soman D. 2005. Attribute evaluability and the range effect. Journal of Consumer Research 32: 363-369. DOI:10.1086/497547.

Zajonc RB. 1968. Attitudinal effects of mere exposure. Journal of Personality and Social Psychology 9(2p2): 1. DOI:10.1037/hoo25848. 